\title{
TARI DALAM SENI PERTUNJUKAN ANGKLUNG BADUD DI DESA PARAKAN HONJE KOTA TASIKMALAYA
}

\author{
Sinta Setiawati \\ Jurusan Pendidikan Seni Tari. Fakultas Pendidikan Bahasa dan Seni. Universitas Pendidikan Indonesia. \\ $\underline{\text { Sintasetia27@gmail.com }}$
}

\begin{abstract}
Abstact
The performing art of Badud Angklung in Parakan Honje Village, Indihiang District, Tasikmalaya City is a typical art from the city of Tasikmalaya by incorporating the results of its unique skills, namely umbrellas and geulis kelom. The problems raised are: 1) What is the form of presentation of Badud Angklung Performing Arts in Parakan Honje Village, Indihiang District, Tasikmalaya City ?; 2) How is the presentation of dance in the Badud Angklung Performing Arts in Parakan Honje Village, Indihiang District, Tasikmalaya City ?; 3) How are the clothes and makeup in the performing arts of Badud Angklung in Parakan Honje Village, Indihiang District, Tasikmalaya City? This research uses the theory of performance studies and descriptive analysis methods with a qualitative approach to describe and explain natural problems related to the performing arts of Badud Angklung and to analyze the form of presentation, the form of presentation of dance and make-up and clothing in the Angklung Badud performance art. It can be concluded that the performing art of Badud Angklung is in the form of parades with the concept of being reproduced, namely adding to the dance and the people who participate in this art, when the procession takes place the movements performed do not have a definite structure while when they form a formation the dance has a definite structure. Namely the geulis umbrella dance and the Badud angklung dance. The male players' make-up is an everyday make-up and the clothes are red and blue and iket to make the traditional elements more visible. Female dancers wear corrective make-up and dress in yellow and use geulis clamps and umbrellas as an identity that this art originates from Tasikmalaya.
\end{abstract}

Keywords: performing arts, Angklung Badud, Indihiang Tasikmalaya, presentation form, dance, make-up, clothing

\section{Abstrak}

Seni pertunjukan Angklung Badud di Desa Parakan Honje Kecamatan Indihiang Kota Tasikmalaya merupakan kesenian khas dari kota Tasikmalaya dengan memasukan hasil keterampilan khasnya, yaitu payung dan kelom geulis. Permasalahan yang diangkat, yaitu :1) Bagaimana bentuk penyajian Seni Pertunjukan Angklung Badud di Desa Parakan Honje Kecamatan Indihiang Kota Tasikmalaya?; 2) Bagaimana penyajian tari dalam Seni Pertunjukan Angklung Badud di Desa Parakan Honje Kecamatan Indihiang Kota Tasikmalaya?; 3) Bagaimana busana dan rias dalam seni Pertunjukan Angklung Badud di Desa Parakan Honje Kecamatan Indihiang Kota Tasikmalaya?. Penelitian ini menggunakan teori performance studies dan metode deskriptif analisis dengan pendekatan kualitatif untuk menggambarkan dan menjelaskan masalah-masalah secara alamiah yang berkaitan dengan seni pertunjukan Angklung Badud dan menganalisis mengenai bentuk penyajian, bentuk penyajian tari serta rias dan busana dalam seni pertunjukan Angklung Badud. Dapat disimpulkan bahwa seni pertunjukan Angklung Badud berbentuk arakarakan dengan konsep diperbanyak yaitu menambah tarian serta warga yang berpartisipasi dalam kesenian ini, ketika arak-arakan berlangsung gerakan yang dibawakan tidak memiliki struktur yang pasti sedangkan ketika sudah membentuk formasi maka tariannya memiliki struktur yang pasti yaitu tari payung geulis dan tari angklung Badud. Rias pemain laki-laki adalah rias keseharian dan busananya berwarna merah dan biru serta iket agar unsur tradisionalnya lebih terlihat. Penari perempuan menggunakan rias corrective dan busananya berwarna kuning serta menggunakan kelom dan payung geulis sebagai identitas bahwa kesenian ini berasal dari Tasikmalaya.

Kata kunci: Seni pertunjukan, Angklung Badud, Indihiang Tasikmalaya, bentuk penyajian, tari, rias, busana.

\section{A. PENDAHULUAN}

Indonesia sangat kaya akan budayanya termasuk didalamnya adalah seni pertunjukan. Menurut Brandon (1967) dalam Soedarsono (1998) mengestimasikan bahwa"seni pertunjukan di Negara-negara Asia Tenggara, tiga-perempatnya adalah milik bangsa Indonesia". Kesenian yang berada di Jawa Barat sangat beragam. Hampir di setiap daerah memiliki kesenian khasnya masing-masing. Pada hakikatnya seni terlahir dari kebiasaan manusia yang diolah sedemikian rupa dengan penghalusan pada berbagai hal sehingga munculah sebuah kesenian. Kesenian akantetap terjaga sampai bertahun-tahun lamanya, hal itu terjadi jika masyarakat setempat memiliki rasa tanggung jawab dalam melestarikan kebudayaannya sendiri. Karya seni yang ada dapat diartikan sebagai hasil karya atau hasil kerja seniman untuk menciptakan sebuah karya yang indah dan dapat diakui masyarakatnya, seperti yang diungkapkan Kasmahidayat (2010 :2) bahwa "Seni adalah keindahan yang merupakan ungkapan jiwa dan budaya manusia terhadap keindahan."

Kebanyakan, masyarakat yang masih peduli terhadap kesenian tradisional adalah 
masyarakat yang berada di pedesaan. Karena mereka memiliki jiwa sosial yang tinggi sehingga sangat peduli terhadap kesenian warisan leluhurnya. Namun masyarakat di perkotaan, mereka lebih memperhatikan perkembangan teknologi dunia dan lupa akan apa yang dimilikibangsanya. Hal ini seperti yang diungkapkan Soedarsono (1998: 1) bahwa

Adapun penyebab dari hidup dan matinya sebuah seni pertunjukan ada bermacam-macam. Ada yang disebabkan oleh karena perubahan yang terjadi dibidang politik, ada yang disebabkan oleh masalah ekonomi, ada yang karena perubahan selera masyarakat penikmat, dan ada pula yang karena tidak mampu bersaing dengan bentuk-bentuk pertunjukan yang lain.

Melihat kenyataan diatas memang sangat menyedihkan sekali, namun pada kenyataanya masih saja ada orang dan sekelompok orang yang peduli dan tetap menjaga kesenian warisan leluhurnya, yaitu masyarakat di Desa Parakan Honje Kecamatan Indihiang Kota Tasikmalaya. di desa ini lah lahir sebuah kesenian yang masih tetap bertahan dan memiliki banyak pecinta dan penikmatnya, yaitu seni pertunjukan AngklungBadud.

Pada zaman dulu mulanya angklungangklung tersebut digunakan pada acara ritual yaitu upacara pertanian menghormati Dewi Sri supaya hasil panennya bagus, namun sekarang pemikiran masyarakat pun lebih maju dan modern sehingga respon masyarakat terhadap hal-hal yang berbau mistispun berkurang. Fungsinya pun kini bergeser menjadi sarana hiburan. Sehingga para masyarakat pecinta angklung pun memutar otak untuk dapat menampilkan pertunjukan angklung dengan tampilan yang lebih menarik agar masyarakat tertarik untuk mengapresiasi kembali pertunjukan angklung yaitu AngklungBadud yang lahir sejak tahum1920-an terus melakukan inovasi agar tampilannya lebih menarik tanpa menghilangkan tradisinya (wawancara: Undang, 2013). Seperti yang diungkapkan oleh Masunah dkk (2003: 2) bahwa

Angklung merupakan salah satu jenis kesenian yang secara historis erat kaitannya dengan adat istiadat dan kepercayaan masyarakat. Namun, perubahan tata kehidupan dan kepercayaan masyarakat mengakibatkan fungsi angklung pun mengalami perubahan. Di beberapa desa, angklung yang berfungsi sebagai sarana ritual padi bergeser atau bertambah fungsinya mengarah ke seni tontonan dalam aneka hajatan.

Di dalam seni upacara ritual terdapat ciri khas yang tidak ada pada seni pertunjukan dan hiburan. Ciri-ciri tersebut patut dilaksanakan untuk kelancaran upacara ritual dan agar tujuan yang diharapkan dapat tercapai. Ciri khas dari upacara ritual biasanya harus ada sesaji untuk Dewi Sri, hari baik untuk dilaksanakan upacara ritual dan lain-lain. Menurut Undang (narasumber) bahwa memang semua hari baik namun dalam seni pertunjukan angklung badudterdapat hari yang harus dihindari untuk penampilan seni pertunjukan angklung badud, yaitu hari sabtu (wawancara: Undang, 2014). Hal tersebut senada dengan yang diungkapkan Soedarsono (1998: 60) bahwa

Walaupun kadarnya bermacammacam, namun secara garis besar seni pertunjukan ritual memiliki ciriciri khas yaitu: 1. Diperlukan tempat pertunjukan yang terpilih yang kadang-kadang dianggap sakral; 2. Diperlukan pemilihan hari serta saat yang terpilih yang kadang-kadangg dianggap sakral; 3 . Diperlukan pemain yang terpilih, biasanya mereka yang dianggap suci atau yang telah membersihkan diri secara spiritual; 4. Diperlukan seperangkat sesaji yang kadang-kadang sangat banyak jenis dan macamnya; 5 . Tujuan lebih dipentingkan daripada penampilan secara estetis; dan 6 . Diperlukan busana yang khas.

Seni pertunjukan angklungbadud adalah pertunjukan musik yang menggunakan angklung dan 4 buah dog-dog serta terdapat tarian khas angklungbadud dan tari payung geulis. Saat ini, AngklungBadud menjadi sulit diterima oleh masyarakat. Faktor yang menyebabkan sulitnya angklungbadud diterima oleh masyarakat diantaranya karena persaingan ketat antara kesenian tradisional dengan kesenian yang lebih modern. Menjadi sebuah masalah apabila kehadiran kesenian tradisional menjadi jarang dalam kehidupan masyarakat karena akan menjadi hambatan dalam penyebaran bahkan penerusan 
kesenian tradisional selanjutnya. Berkembangnya pola pikir masyarakat yang lebih maju ke arah modern mempengaruhi keberadaan kesenian tradisional. Selain itu, faktor lain yang menyebabkan kesenian tradisional menjadi jarang adalah karena dana. $\quad$ Soedarsono (1998: 47) mengungkapkan bahwa" Pertunjukanpertunjukan ritual penyandang dana produksinya adalah masyarakat, oleh karena pertunjukan sejenis ini yang penting bukanlah bentuk ungkap artistiknya, melainkan tujuannya". Oleh karena pada zaman dulu tujuan pertunjukan angklung adalah untuk ritual panen maka dananya ditanggung oleh seluruh masyarakat setempat. Dikarenakan kini karena fungsinya sudah bergeser menjadi hiburan maka dana yang dikeluarkan kini dari orang yang mampu membayar para pemain, dan dana yang dibutuhkannya pun tidaklah sedikit. Oleh karena itu tidak sembarang orang yang bisa mendanai pertunjukan angklung.

Tarian dalam Pertunjukan seni AngklungBadud sudah menjadi satu paket dalam tampilannya dan tidak dapat dipisahkan. Undang merupakan pimpinan di Paguyuban Gentra Parhon. Ia sengaja memodifikasi pertunjukan seni AngklungBadudagar lebih bisa diterima masyarakat, seperti pada tariannyayang menyertakan properti khas Tasikmalaya yaitu payung geulisdan kelom geulisagar menjadi identitas seni pertunjukan AngklungBadud dari Kota Tasikmalaya. Sebenarnya pada awalnya, pertunjukan angklungbadud hanya menampilkan tarian angklungbadud yang diciptakan oleh Cica dan Meli(koreografer tari angklungbadud) pada tahun 1997-an. Masih dalam tahun yang sama namun berbeda bulan karena permintaan dari Dinas Kebudayaan dan Pariwisata Kota Tasikmalaya agar menyisipkan keterampilan khas Tasikmalaya yang lainnya maka dibuatlah tari payung geulis. Soedarsono (1998: 52) mengatakan bahwa " Dengan hadirnya era globalisasi, para seniman memiliki kebebasan untuk menampilkan gaya yang mereka senangi”. Selain itu yang khas pada tarian dalam seni pertunjukan AngklungBadud adalah para penari di akhirpertunjukan penari wanita paling cantik dan kecil akan menaiki jampana dan 2 orang lainnya menaiki kuda lumping, ketika pertunjukan berakhir penari menaiki kuda lumping akan turun tetapi penari yang menaiki jampana tetap duduk di jampana. Fungsi dari seni pertunjukan AngklungBadud dulunya adalah untuk upacara ritual panen sehingga waktu pertunjukannya sangat terbatas yaitu hanya pada saat panen dan pada daerah tertentu saja, namun kini fungsinya bergeser kepada sarana hiburan sehingga pertunjukannya bisa disaksikan kapanpun, dimanapun dan untuk siapapun. Saat ini, seni pertunjukan AngklungBadud ditampilkan pada acara pernikahan, sunatan, acara-acara kesenian di luar kotasampai ke acara-acara besar yang diadakan di Tasikmalaya.

Dari kenyataan di atas maka peneliti tertarik untuk melakukan penelitian dan memutuskan untuk meneliti bentuk penyajian, tari, busana dan rias Seni PertunjukanAngklungBadud di Desa Parakan Honje Kecamatan Indihiang Kota Tasikmalaya. Metode penelitian yang peneliti gunakan dalam melakukan penelitian terhadap seni Pertunjukan AngklungBadud adalah metode deskriptif analisis dengan pendekatan kualitatif

\section{B. HASIL DAN PEMBAHASAN}

1) AnalisisPenyajian Seni Pertunjukan AngklungBadud di Desa Parakan Honje Kecamatan Indihiang Kota Tasikmalaya

Seni pertunjukan angklungBadud yang disajikan mulai dari tahap persiapan hingga tahap akhir dipersiapkan dengan begitu matang, segala macam yang berkaitan dengan rute, properti, urutan pemain dan lain-lain semuanya dikonsep dengan teliti. Terbukti ketika saat pertunjukann berlangsung urutan pemain mulai dari tahap persiapan, tahap arak-arakan hingga tahap akhir semuanya tersusun rapi hingga acara sunatan pun dapat berlangsung lancar. Hal tersebut diterapkan untuk kebutuhan nilai estetis pertunjukan supaya terkesan lebih rapi dan terkonsep. Arak-arakan adalah berjalan cukup jauh dengan pemain yang berbaris panjang ke belakang, dalam pertunjukan arak-arakan ini menggunakan konsep diperbanyak yakni dalam hal tarian yang awalnya hanya tari angklungbadudmenjadi tari angklungbaduddan tari payung geulisserta warga yang semakin banyak mengikuti arak-arakan dalam seni pertunjukan AngklungBadud. Dari awal hingga akhir arak-arakan posisi pemain tidak mengalami perubahan, yaitu pawang di depan karena selalu mengawasi pemain kuda lumping sekaligus menjadi pemimpin 
barisan lalu disusul pemain kuda lumping kemudian penari angklungBadud dan payungg geulis dan di urutan palingbelakang adalah para pemain tarompet, dog-dog hingga angklung.

Pemain seni pertunjukan angklungBadud terdiri dari berbagai generasi. Para penari tari angklungBadud dan payungg geulis rata-ratanya adalah anakanak yang baru duduk di sekolah menengah atas, sedangkan yang lainnya ada yang berumur sekitar 20 tahuan hingga para orang tua. Memasukan para anak dibawah umur ini bisa membuat seni pertunjukan angklungBadud terlihat lebih fresh dan bisa diterima oleh berbagai kalangan (umur). Selain itu, hal ini juga dilakuakan sebagai usaha pemimpin seni pertunjukan angklungBadud agar terjadi penurusan warisan kepada generasi muda agar seni pertunjukan angklungBadud tidak punah ketika para orang tua sudah tiada.

Penyajian seni pertunjukan angklungBadud disajikan dengan begitu meriah. Hal ini terlihat dari semangatnya para pemain seni pertunjukan angklungBadud mulai dari pawang, para penari hingga para pemain alat musik memainkan perannya masing-masing. Ditambah pula dengan suara musik yang kencang membuat warga sekitar yang dilalui barisan arak-arakan ikut bergabung dan menari bersama para pemain, bahkan tidak sedikit warga yang ikut melakuakan arakarakan hingga akhir. Pada dasarnya, zaman dahulu seni pertunjukan angklungBadud berfungsi sebagai upacara ritual panen yang dilakuakan oleh banyak orang secara bergotong royong. Hal tersebut memiliki makna bahwa manusia merupakan makhluk sosial yang membutuhkan bantuan orang lain dan tidak dapat berdiri sendiri. Begitu pula dengan seni pertunjukan angklungBadud yang tidak bisa hanya dimainkan oleh satu orang pemain angklungsaja. , tetapi harus oleh banyak orang yang memiliki peran yang berbeda.

\section{2) Analisis Penyajian Tari dalam Seni Pertunjukan AngklungBadud di Desa Parakan Honje Kecamatan Indihiang Kota Tasikmalaya}

Seni pertunjukan angklungBadud menyajikan 2 tarian dalam pertunjukannya, yaitu tari payung geulis dan tari angklungBadud, yang kemudian dipadukan dengan unsur musik yang semakin memeriahkan suasana. Selain tarian-tarian tersebut terdapat pula tarian kuda lumping, namun tari kuda lumping tidak memiliki struktur gerak yang tetap mereka hanya memainkan propertinya saja dengan gerakan ke atas ke bawah kemudian ke samping kanan dan kiri. Tarian pada seni pertunjukan angklungBadud pada awalnya para penari perempuan yang berjumlahh 4 orang melakuakan arak-arakan dan gerakan yang dilakukan adalah gerakan sederhana seperti mengayunkan tangan kanan dan kiri ke depan dan belakang secara bergantian lalu gerakan memainkan sampur oleh kedua tangan mereka. Hal ini dikarenakan seni pertunjukan angklungBadud adalah seni arak-arakan sehingga para penari tidak mungkin melakuakn gerak yang rumit pada saat berjalan jauh, mereka harus tetap menjaga stamina mereka agar bisa melalui rute yang telah dibuat. Ketika sedang arakarakan para pemain musik membawakan musik boboyongan, bribil dan buncis secara bergantian. Ketika awal memainkan musik maka yang memimpin adalah angklung no 1 sedangkan yang memberi aba-aba musik berhenti adalah pemain dog-dog no 2 atau dog-dog catrik. Seperti halnya penari kuda lumping, pemain angklung dan dog-dog pun melakukan gerakan sederhana seperti memiringkan badannya ke samping kanan dan kiri mengikuti irama musik.

Setelah arak-arakan selesai maka barisan pemain seni pertunjukan angklungBadud akan memasuki lapangan yang telah disediakan pihak penyelenggara untuk melakukan persembahan terakhir yang pertama yaitu membawakan tari payung geulis dengan iringan musik buncis kemudian setelah itu dilanjutkan oleh penyajian tarian angklungBadud dengan musik boboyongan, bribil dan buncis secara bergantian dengan aba-aba perindahan lagu oleh dalang atau pemain angklung no 1 . Ketika perpindahan tarian dari payunggeulis ke tari angklungBadud properti payunggeulisakan diamankan oleh seorang crew. Ketika semuanya selesai maka semua barisan pemain seni pertunjukan angklungBadudakan berputar membentuk lingkaran lalu meninggalkan lapangan.

Kehadiran tari payung geulis dan tari angklungBadud dalam seni pertunjukan angklungBadud merupakan bagian penting yang tidak dapat dipisahkan dari seni pertunjukan angklungBadud. Hal ini dikarenakan, menambah daya tarik dari pertunjukan ini serta untuk menyeimbangkan 
agar tidak hanya audionya saja yang disuguhkan kepada para penonton tetapi juga visualnya berupa tarian.

\subsection{Analisis Struktur Gerak Tari dalam Seni Pertunjukan AngklungBadud di}

\section{Tabel 1}

Analisis gerak tari angklungBadud dalam seni pertunjukan angklungBadud

\begin{tabular}{|c|c|c|c|}
\hline No & Nama Gerak & Deskripsi Gerak & Kategori Gerak \\
\hline 1 & Ulin sampur & $\begin{array}{l}\text { Gerakan pertama didominasi oleh } \\
\text { gerakan memainkan sampur di } \\
\text { tempat dengan bergantian ke kiri } \\
\text { dan kanan. }\end{array}$ & Pure movement \\
\hline 2 & Mincid & $\begin{array}{l}\text { Gerakan kedua didominasi oleh } \\
\text { pergerakan kaki dan tangan di } \\
\text { tempat namun arah hadap } \\
\text { bergantian ke kiri dan ke kanan. }\end{array}$ & Pure movement \\
\hline 3 & Sabet tangan & $\begin{array}{l}\text { Gerakan ketiga juga seperti halnya } \\
\text { gerakan kedua lebih didominasi } \\
\text { oleh gerakan tangan dan kaki yang } \\
\text { diangkat sedikit dan arah hadapnya } \\
\text { bergantian ke kiri dan ke kanan. }\end{array}$ & Pure movement \\
\hline 4 & Engkle & $\begin{array}{l}\text { Gerakan ke empat adalah gerak } \\
\text { yang lebih memainkan kaki } \\
\text { kemudian berputar di tempat. }\end{array}$ & Locomotion \\
\hline 5 & Jalan mundur & $\begin{array}{l}\text { Gerak ke lima adalah gerak seperti } \\
\text { berjalan biasa dengan arah hadap } \\
\text { ke belakang penonton. }\end{array}$ & Locomotion \\
\hline 6 & $\begin{array}{l}\text { Kepret } \\
\text { sampur }\end{array}$ & $\begin{array}{l}\text { Gerakan ke enam adalah gerak } \\
\text { merambat atau mapay sampur } \\
\text { dengan tangan kemudian ketika } \\
\text { dibagian ujung sampur dibuang } \\
\text { kearah belakang. }\end{array}$ & Pure movement \\
\hline 7 & Nangreu & $\begin{array}{l}\text { Gerak dengan posisi tangan lurus } \\
\text { namun sedikit turun dan telapak } \\
\text { tangan tegak. Gerakan nangreu } \\
\text { tidak mengalami perpindahan } \\
\text { tempat. }\end{array}$ & Pure movement \\
\hline 8 & Meber sampur & $\begin{array}{l}\text { Gerak membentangkan sampur } \\
\text { oleh kedua tangan dengan tempo } \\
\text { yang sedang atau tidak lambat juga } \\
\text { tidak cepat. Gerakan ini tidak } \\
\text { mengalami perpindahan tempat } \\
\text { penarinya. }\end{array}$ & Pure movement \\
\hline 9 & $\begin{array}{l}\text { Nyangigir } \\
\text { nyampur }\end{array}$ & $\begin{array}{l}\text { Gerakan penari memegang kedua } \\
\text { ujung sampur dan kakinya } \\
\text { melangkah ke kiri dan kanan } \\
\text { dengan tangan menyiku dan kaki } \\
\text { menyilang, namun tidak } \\
\text { melakukan perpindahan tempat } \\
\text { hanya perpindahan arah hadap } \\
\text { saja. }\end{array}$ & Pure movement \\
\hline 10 & Sembah & $\begin{array}{l}\text { Gerak terahir ini adalah gerak yang } \\
\text { dilakukan pada level rendah } \\
\text { dengan tangan menyembah yang } \\
\text { memiliki makna melakuakan }\end{array}$ & Gesture \\
\hline
\end{tabular}

\section{Desa Parakan Honje Kecamatan Indihiang Kota Tasikmalaya \\ 2.1.1 Tari angklungBadud}




\begin{tabular}{|l|l|l|}
\hline & $\begin{array}{l}\text { penghormatan kepada tamu-tamu } \\
\text { yang sudah hadir. }\end{array}$ & \\
\hline
\end{tabular}

Berdasarkan analisis di atas, maka gerak-gerak yang terdapat pada tari angklungBadud sebagian besar merupakan kategori gerak murni (pure movement) seperti gerak ulin smapur, minced, sabet tangan, kepret sampur, nangreu, meber sampur dan nyangigir nyampur. Adapula yang termasuk kategori gerak berpindah tempat (locomotion) yaitu gerak engkle, gerak jalan mundur serta terdapat satu gerak yang termasuk gerak maknawi (gesture) yaitu gerak sembah yang memiliki makna penghormatan kepada orang-orang yang datang.

\subsubsection{Tari payung geulis}

Tabel 2

Analisis gerak tari payung geulis dalam seni pertunjukan angklungBadud

\begin{tabular}{|c|c|c|c|}
\hline No & Nama Gerak & Deskripsi Gerak & Kategori Gerak \\
\hline 1 & ulin sampur & $\begin{array}{l}\text { Gerak pertama ini adalah gerak } \\
\text { memainkan sampur tanpa adanya } \\
\text { perpindah tempat hanya } \\
\text { perpindahan arah hadap saja. }\end{array}$ & Pure movement \\
\hline 2 & Ulin payung & $\begin{array}{l}\text { Gerak kedua ini lebih menonjolkan } \\
\text { permaian payung geulisyang } \\
\text { diangkat kemudian berpindah } \\
\text { tangan lagi menjadi dibawah. }\end{array}$ & Pure movement \\
\hline 3 & $\begin{array}{c}\text { Nyanghareup } \\
\text { nyiku }\end{array}$ & $\begin{array}{l}\text { Gerak ini adalah gerak memainkan } \\
\text { tangan yang tidak memegang } \\
\text { payung. Gerak ini tidak } \\
\text { mengalami perpindahan tempat } \\
\text { penarinya. }\end{array}$ & Pure movement \\
\hline 4 & Muter payung & $\begin{array}{l}\text { Gerakan ini menonjolkan } \\
\text { permainan payung yang diputar- } \\
\text { putar bagian ujung batangnya oleh } \\
\text { tangan sambil melakuakn putaran } \\
\text { badan sehingga terjadi } \\
\text { perpindahan posisi penari }\end{array}$ & Locomotion \\
\hline 5 & Nurun payung & $\begin{array}{l}\text { Gerak ini sama halnya dengan } \\
\text { yang lain yaitu memainkan payung } \\
\text { yang membuat payung posisinya } \\
\text { menjadi dibagian bawah tubuh kita } \\
\text { sehingga penonton bisa Melihat } \\
\text { bagian dalam dari } \\
\text { payunggeulistersebut. }\end{array}$ & Pure movement \\
\hline 6 & $\begin{array}{l}\text { Ngangkat } \\
\text { payung }\end{array}$ & $\begin{array}{l}\text { Gerak ini sama halnya dengan } \\
\text { yang lain yaitu memainkan payung } \\
\text { yang membuat payung posisinya } \\
\text { menjadi dibagian atas tubuh kita } \\
\text { sehingga penonton bisa Melihat } \\
\text { bagian atas dari } \\
\text { payunggeulistersebut. }\end{array}$ & Pure movement \\
\hline 7 & Maju & $\begin{array}{l}\text { Gerakan ini adalah gerakan } \\
\text { berjalan sambil membawa payung } \\
\text { di pundak kearah penonton bagian } \\
\text { depan. }\end{array}$ & Locomotion \\
\hline 8 & Mundur & $\begin{array}{l}\text { Gerakan ini adalah gerakan } \\
\text { berjalan sambil membawa payung } \\
\text { di pundak ke arah penonton bagian } \\
\text { belakang sehingga penonton } \\
\text { bagian depan bisa Melihat bagian }\end{array}$ & Locomotion \\
\hline
\end{tabular}




\begin{tabular}{|l|l|l|}
\hline & $\begin{array}{l}\text { belakang tubuh penari dan bagian } \\
\text { atas payunggeulis. }\end{array}$ & \\
\hline
\end{tabular}

Berdasarkan analisis di atas, gerak-gerak yang terdapat pada tari payung geulis sebagian besar merupakan gerak murni (Pure movement) di antaranya gerak ulin sampur, ulin payung, nyanghareup nyiku, nurun payung dan ngangkat payung. Terdapat pula gerakan yang termasuk gerak berpindah yaitu seperti pada gerak muter payung dan gerak maju serta mundur.

Dari paparan semua analisis tentang gerak Tari payung geulis dan tari angklungBadud dalam seni pertunjukan di atas, gerak-geraknya menggunakan gerak pure movement atau gerak murni, dangerak maknawi (gesture)dangerak berpindah tempat (locomotion) untuk berjalan sebagai kebutuhan artistik dan keindahan dalam arak-arakan.

\section{3) Analisis Rias dan Busana dalam Seni \\ Pertunjukan AngklungBadud di Desa Parakan Honje Kecamatan Indihiang Kota Tasikmalaya}

Dari pemaparan rias dan busana dalam seni pertunjukan angklungBadud, peneliti menganalis sebagai berikut. Ada dua macam rias yang digunakan oleh pemain seni pertunjukann angklungBadud, yaitu rias corrective dan rias natural atau keseharian. Yang menggunakan rias corrective adalah penari payung geulis dan penari angklungBadud yang menggunakan warna make up yang cerah seperti eye shadow warna hijau, blush on pink dan lipstick merahnamun tidak mencolok karena rias ini bukanlah kebutuhan untuk lighting sehingga pemakaian riasnya tidak berlebihan. Pemain angklung, dog-dog, tarompet, pawanghinggapenari kuda lumping semuanya menggunakan rias keseharian atau natural karena tidak diperlukan penonjolan karakter.

Busana para pemain dan penari dalam seni pertunjukan angklungBadud memakai busana yang aman, nyaman, serasi namun enak dilihat walaupun busana yang digunakan adalah busana orang sunda jaman dahulu atau tradisional. Penari payung geulis dan angklungBadud merupakan penari dengan orang yang sama sehingga busana yang digunakan adalah sama yaitu kebaya dan sinjang. Penari kuda lumping, pawang, pemain $d o g$ - $d o g$, angklung hingga tarompet menggunakan pangsi walaupun warna berbeda-beda tetapi masih sama-sama pangsi. Hal ini dikarenakan agar memberikan kenyamanan pemain dalam melakukan gerak, karena dalam seni pertunjukan angklungBadud berbentuk arakarakan dan pasti akan pemain akan merasa kegerahan sehingga disesuaikanlah busananya kain tipis yang dinamakan pangsi untuk menyerap keringat pemain sehingga pemain akan tetap aktif bermain musik. Untuk pemain dog-dog dan angklung,dodot yang digunakan adalah kain polos senada dengan iket kepala sedangkan pawang menggunakan sinjang batik yang motifnya sama dengan iket kepala serta penari kuda lumping dan tarompet tidak menggunakan sinjang. Pawangmembawa taskaneron yaitu tas kecil yang bermotif dan berbahan anyaman, tas ini digunakan untuk menambah unsur tradisional yang ada dalam seni pertunjukan AngklungBadud.

Tidak hanya dalam warna busana para pemain seni pertunjukan angklungBadud terlihat bervariasi, tetapi juga dalam bentuk iket yang digunakannya. Para pemain lakilaki dalam seni pertunjukan angklungBadud semuanya menggunakan iket tanpa terkecuali sebagai ciri khas laki-laki sunda. Dalam pemakaiannya bervariasi, ada yang menutupi seluruh kepala, ada yang bagian atas kepala masih terlihat dan ada pula bagian ujung iket tergerai dibelakang. Jenis-jenis iket yang digunakan terdapat macam, yaitu:

1. Iket kepala kuda ngencar

2. Iket kreasi, walapun namanya kreasi namun bentukmya bermacam-macam, ada yang ujungnya menjuntai panjang dan ada yang pendek

Unsur tradisional lainnya yaitu hiasan kepala penari yang menggunakan hiasan bunga-bunga sederhana. Hal ini memperlihatkan bahwa gadis tersebut berasal dari kalangan rakyat sunda, sehingga sangat nampak sekali identitas daerah dalam seni pertunjukan angklungBadud ini.

\section{SIMPULAN}

Seni pertunjukan angklungBadudadalah hasil kreatifitas dan inovasi dari seniman, koreografer dan Dinas Pariwisata dan Kebudayaan yang bertujuan agar seni pertunjukan angklungBadudtetap lestari. Hal ini juga dilakukan agar masyarakat kembali menyukai seni pertunjukan 
AngklungBaduddan bisa menjadi kebanggaan dan dijadikan kesenian khas dari Kota Tasikmalaya.

Seni pertunjukan

AngklungBadudmerupakan konsep arakarakan yang dibuat lebih semarak dengan menambahkan tarian yang dicampurkan dengan keterampilan khas Kota Tasikmalaya sehingga ketika daerah lain atau masyarakat luar Kota Tasikmalaya yang menonton seni pertunjukan AngklungBadudakan langsung mengetahui bahwa seni pertunjukan AngklungBadudberasal dari Kota Tasikmalaya. Tarian mulai muncul dengan struktur yang tetap pada tahun 1997-an, tarian diciptakan ada 2 macam yaitu pertama tari angklung badud kemudian beberapa bulan kemudian diciptakan tari payung geulis. Agar seni pertunjukan AngklungBadudlebih semarak maka properti tarian berupa payung geulis menggunakan warna-warna cerah dan beragam sehingga terlihat lebih ceria dan menarik perhatian masyarakat. Selain itu seni pertunjukan AngklungBadud menerapkan konsep warna pada busana penari dan pemain alat musik, yaitu menggunakan warna-warna cerah seperti kuning terang, merah terang dan lainlain. Penggunaan iket yang digunakan oleh pemain dog-dog, angklung, tarompet, pawanghingga penari kuda lumping beragam agar unsur tradisionalnya lebih kental dan lebih semarak lagi.

Kehadiran tari angklungBadud dan tari payung geulis dalam seni pertunjukan AngklungBadud merupakan hal penting yang tidak dapat dipisahkan karena untuk menyeimbangkan agar masyarakat tidak hanya disuguhi unsur audionya saja melainkan juga unsur visualnya.

\section{DAFTAR PUSTAKA}

Kasmahidayat, Yuliawan. (2010). Agama dalam Transformasi Budaya Nusantara. Bandung: Bintang Warliartika.

Masunah, Juju dkk. (2003). Angklung di Jawa Barat Sebuah Perbandingan. Bandung: PAST UPI.

Soedarsono, R. M. (1998). Seni Pertunjukan Indonesia Di Era Globalisasi. Jakarta: Direktorat Jendral Pendidikan Tinggi Departemen Pendidikan dan Kebudayaan 